\title{
Shaping the Gender Socialization Through Different Models of Behavior
}

\author{
Dr. Elvira Dode \\ University "A. Xhuvani” Elbasan, Faculty of Education Sciences, Social Sciences Department \\ dode01@hotmail.com
}

\section{Doi:10.5901/ajis.2015.v4n2p27}

Abstract

\begin{abstract}
Gender equality education prepares civics who takes responsibilities for social, politic, economic issues and even for democratization processes. Its social effect, if it is not treated carefully may lead into the discrimination of some individual's categories according to gender basis. The consciousness and the commitment for achieving gender equality are reflected even in the policies and strategies for education development. Including gender perspective in schools is a prerequisite inalienable of human development, instead insuring gender equality it is considered as respecting human rights. School environment, community and other actors have their influence into the creation of a perfect climate for realizing the education process in the most effective way. Attitudes, parents and teachers behaviors are seen as a role model and affect the civic education of pupils. From the other side, they help into solving the gender problems of pupils. Comparing the ratio of gender stereotypes exposure between attitudes and stands in the education system we conclude that there is a need for increasing the care that must be shown for integrating the gender education in the civic education framework of students. The scope of the undertaken study is to perform the scale and shape in which gender stereotypes are portrayed and shown in social life and their affect in the education for a democratic society. To achieve this scope, we use the method of studying the existing literature; a detailed analysis of the questionnaires and interviews content with school directors and teachers of pre-graduated education conducting researches abroad geographical extension in cities: Shkodër, Tiranë, Elbasan, Pogradec, Korçë. Nurturing the values of democratic culture, spiritual emancipation and open mind, enables shaping healthy individuals ready to contribute to the proper well-functioning society.
\end{abstract}

Keywords: civic formation, gender education, social effect, role model, sensitivity.

\section{Introduction}

Gender awareness is an important dimension of capacity building and intends to promote gender equality and foster equal opportunities in schools, family and communities regarding gender roles, so impacting both the school and the society. The goal of the education system reflects community values (David, 1984).

Inequalities between men and women as well as among other social groups can be minimized by means of education (UNDP, 2005). The National Policy of Education, alongside reforms in this sector and the National Action Plan, has intended to achieve gender equality in education until 2015. The National Strategy for pre-graduating education 2004-2015 intend to influence educational policies right from the formulation and implementation down to the accountability regarding the monitored effects about which the education service has been set up. The National Strategy for Gender Equality, Violence to Women and Violence in the Family - NSGEVWVF, (2011-2015), has clearly defined the achievement of gender equality, that is, by eleminating gender stereotypes (MAS).

Gender inequalities in the education system can be addressed by measurable indicators. The content of the curricula, school texts, interactive relations teacher-students, the institutional ambiance etc., by means of messages they render, play an important role in preserving and transmitting stereotypes and gender inequality.

This study accentuates the need for simultaneous collaboration and intervention of all the crucial actors of education; students, families, teachers, the society and more, to create effective means for avoiding and even eleminating gender stereotypes. The scope of the undertaken study is to perform the scale and shape in which gender stereotypes are portrayed in the context of the role and the interaction of different actors in the education process.

Hewstone (1989) mentions three main methods to change stereotypes: 1.The individualization technique. This technique focuses on the individual characteristics of each out-group member rather than the group attribute as a whole. The effect of this technique can be even stronger when the unique characteristic of the individual is inconsistent with the group attribute. 2. The contact hypothesis. The content of this hypothesis is that by increasing direct contact with outgroup members, one may gain knowledge about the out-group individuals and thus hold less stereotypical assumptions 
about them. The fostering environment for this hypothesis is cooperative interactions between group members on an equal footing, doing tasks of high probability of success and an atmosphere free of tension or conflict. 3 . The belief that people hold on to stereotypes in order to satisfy some particular needs. If people are aware that their needs will be better satisfied when they alter the stereotypes rather than maintaining them, this can also be a motivation for stereotype change (Hewstone, 1989).

The proper evaluation and consideration of this study, regarding the persistence and the various effects of the gender discrimination forms as well as the availability of the educational institutions to adjust their academic curricula, will increase community awareness to problems related with gender.

\section{The Theoretical Aspect}

There exist three main approaches regarding the child gender development; the psychoanalytical prospective, (Freud, 1925), the processes of social learning, (Bandura, 1986) and the cognitive processes, (Mischel, 1970). Cognitive processes involve three theories: the theory of social learning, the theory of cognitive development and the theory of gender schemes.

According to the theory of the gender roles, represented by Talcott Parsons, the society defines specific stereotypical roles to any members of the respective genders. These sterotypes have been acquired by girls/women in the socialization process and have been preserved by boys/men. Connell argues that sterotypical inclinations are the cause of the women's disadvantages (Connell, 1987). For this reason and, according to this attitude, gender inequality can definitely be eleminated by means of special measures suchlike the elemination of the stereotypical models, affirmative action plans, better education, (including anti-discrimination curricula), and equal treatment of girls by the legislation in force (Risman, 2004).

The forces drawing children back to traditional norms include the start of puberty, parental influences and dating with member of the opposite sex. Puberty introduces changes in children's bodies, causing them to have a stronger sense of being females and males. Together with these new signals, parents seem to encourage their children to conform to gender norms at a greater extent than before. And lastly, children believe that to be a closer imitation to the typical models of their gender, they become more attractive to the other sex (Banerjee, 2005).

Not only that young child believe the sex stereotypes to be true, they use this knowledge of gender as the sole resource in making inferences about other individuals (Golombok \& Fivush, 1994) and (Berk, 2003). The amount of gender stereotypes each individual have differs from that of others, and even between different periods in their life. I suppose there is nothing like "the real concrete difference" that females and males are destined to have. Each of those powerful forces enters and varies in people's life at different points, and in the meanwhile, other new influences keep adding on (Berk, 2003) and (Burns, 1994).

The various socialization groups such as family, the school, group members and mass media should do their work to build whole series of models of behaviour for each gender. This is the way the gender socialization has been built (Connell, 1987). The socializing factors; parents, family members, peers, teachers and the experiences obtained in the social context and in the community have their impact into shaping gender stereotypes. The way teachers and the school transmit gender stereotypes indirectly has been known as the "hidden curricula". In general, boys receive more attention from teachers than girls, (Golombok \& Fivush, 1994). It has not yet been proven whether boys are really more creative than girls, but the hidden message transmitted by teachers is clear; there are activities that boys can do but girls cannot (Burns, 1994).

"The cultural stereotypes represent a community wide, consensual set of beliefs" whereas "individual stereotypes are a set of associations held by an individual about a social group" (Dovidio at al. 1996). Social differentiation involves identifying and highlighting the differences between groups, aiming at placing the in-group at a superior position (Tajfel, 1981). It can also be in the other way when people observe behaviors of individuals, then with available stereotypical knowledge, make predictions of which social groups the observed individuals are members of (Stangor \& Schaller, 1996).

The widely use of gender stereotypes in adulthood stems from earlier stages in childhood. Blocking the development of gender stereotypes reduces the need to control ... stereotyping and its effects later in life."(Zamora, at al. 2000). An early intervention is bound to be more successful than trying to control stereotypes at later stages. ... Efforts to control well-practices stereotypes exact heavy costs. So much the better to start young (Eckes \& Trautner, 2000). 


\section{Methodology}

Most of qualitative research scholars, basing on interviews and quastionnaires suggest intended use sampling. The intended use sampling selected for study is based on such prerequisites as; the preservation of gender equality, including the representatives of the three pre-university cycles in sampling; the elementary cycle, (grades IV, V), the lower secondary education, (grades $\mathrm{VI}-\mathrm{IX}$ ) and the higher secondary education, (grades $\mathrm{X}-\mathrm{XII}$ ). To this regard the feedback by a variety of authors regarding the effects of gender problems in the teaching-learning processes in education has been analyzed. The following is the kind and number of the contacted actors;

1 Interest groups from 15 schools selected from different countries of Albania, suchlike Elbasan,Tiranë, Shkodër, Pogradec, Korçë, including five elementary schools, 5 schools of the lower secondary education, 5 schools of the higher secondary education, distributed evenly in urban zones.

1. Interviews with school directors 28.

2. Questionnaires with parents 80 .

3. Questionnaires with teachers 120

4. Questionnaires with students 246

Strategies and means used to collect primary data are the following;

1. Analyzing the qualitative and quantitative content of the interviews;

2. Interviews with school directors

3. Questionnaires with teachers, students and parents.

\section{Outcomes of the Study}

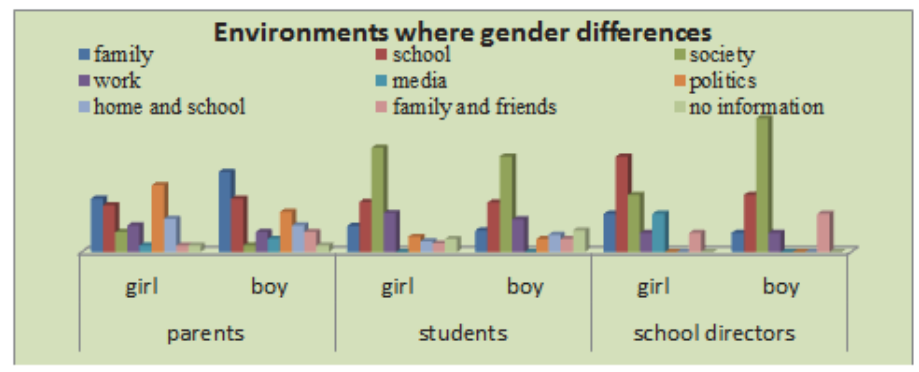

Chart 1. Opinions about the ambiances where gender gaps have been displayed.

Participants from three categories of sampling share the same opinion about the ambiances the gender gaps are displayed but there are differences regarding each single ambiance. Parents say that gender discrimination occurs more in schools, to an incidence of $30 \%$ and in community /society to $20-30 \%$. Students think that there is more gender discrimination in the society, to an incidence of $42 \%$. The school directors are divided in their opinions; $35.71 \%$ of women think the incidence is greater in school ambiances whereas $65.29 \%$ of men think the incidence is greater in the society.

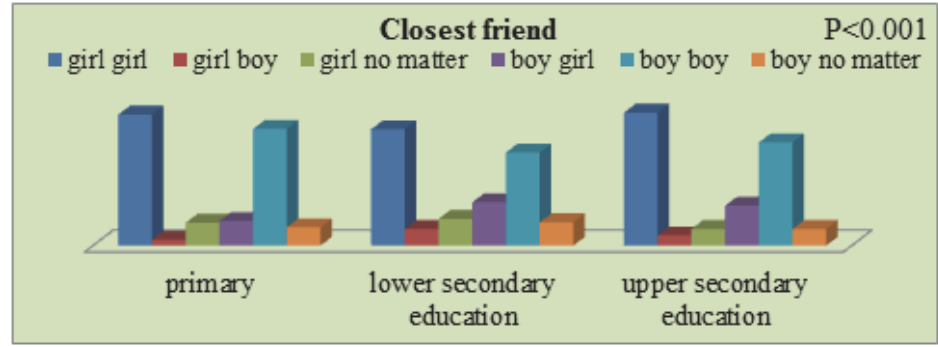

Chart 2. The students' gender preferences for their closest friends.

Parents share different opinions regarding the effects of gender in selecting female/male friends from their children. The number of mothers thinking that gender has no effects to this regard is 1.5 times greater than that of fathers. The number 
of fathers saying that they have no information regarding the effects of gender to their children's company selections is $2.50 \%$ greater than mothers'.

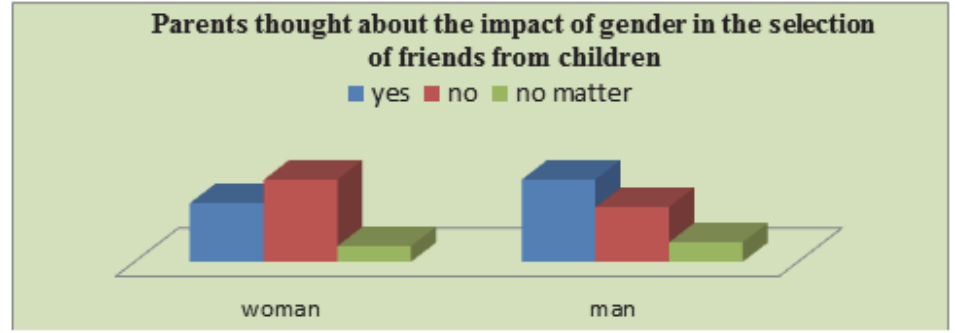

Chart 3. The students' gender preferences for their close female/male schoolmate.

In the elementary cycle of education the number of boys selecting girls to be their friends is 5 times greater than number of girls selecting boys to be their friends. In the lower secondary education this distinction is reduced to 2.7 times, since there is an increase of the percentage of the girls selecting boys as their friends. The distinction between genders is increased in the higher secondary education. The number of boys selecting girls as their friends is 4 times greater.

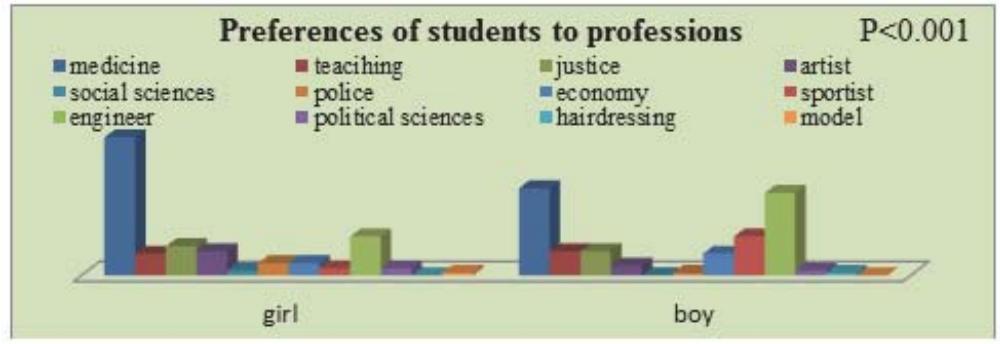

Chart 4. Students' preferences for the profession they want to have in the future.

The most favorable profession for both genders is medicine, amounting to 46.34\% - 29.27\%. Girls prefer medicine 1.6 times more than boys. Second place takes engineering with $27.64 \%$ for boys and $13.01 \%$ for girls, boys prefer engineering twice more than girls. For boys sports take third place with $13.01 \%$, whereas for girls are law studies with $9.67 \%$.

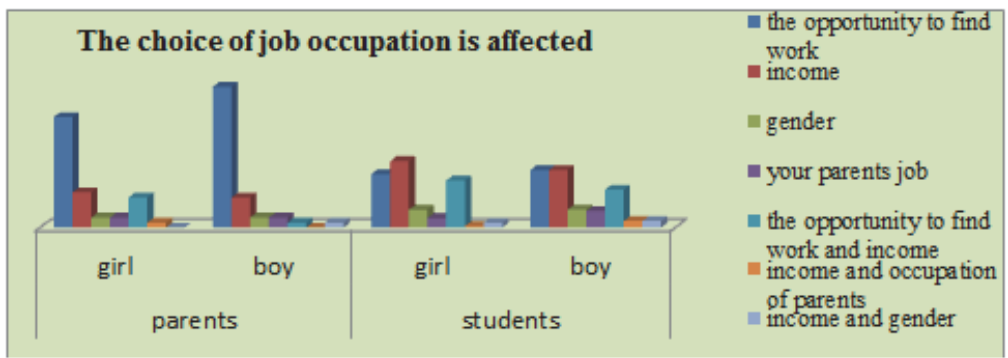

Chart 5. Parents and students' opinion regarding their opportunities in choosing professions.

Employment opportunities are ranked as one of the main factors effecting selection of the professions by $55.00 \%$ $70.00 \%$ of parents and $26.83 \%-28.46 \%$ of students. $5.00 \%$ more girls than boys rank the incomes as the main cause. This percentage keeps growing if both factors of employment opportunities and incomes are taken together. 


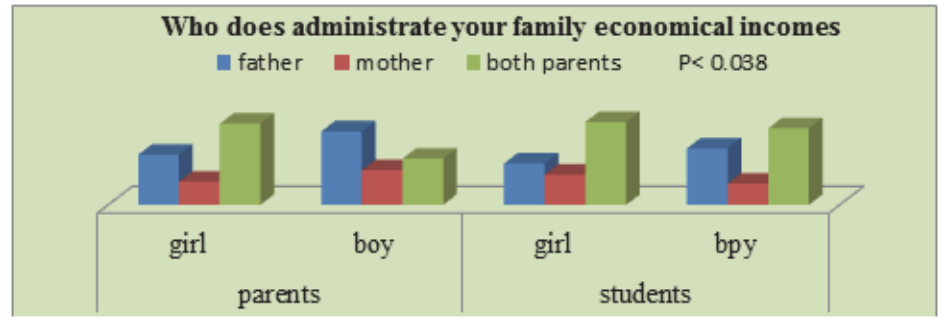

Chart 6. Parents and students' opinion regarding administration of financial incomes.

Role of parents in decision making is connected with their influence in administering financial incomes in the family. $1 / 2$ of the participants in the study think administration is realized by both parents, this mostly reported by schoolgirls with $52.66 \%$. $1 / 3$ of the participants think administration is made by fathers, which is more reported by fathers with $47.50 \%$ and boys with $36.59 \%$.

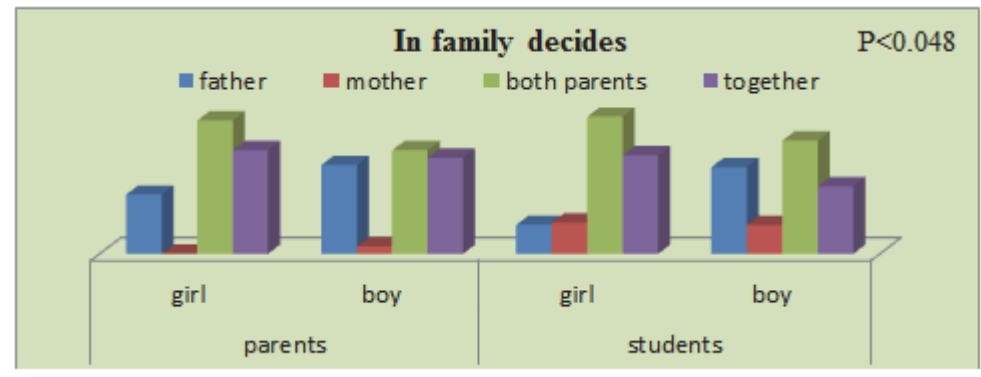

Chart 7. Parents and students' opinions regarding decision making in the family.

Both categories of the participants and both genders report mostly that fathers only decide in the family. Fathers themselves, 1.5 times more than mothers and 3 times more boys than girls declare about the decisive role of fathers in the family. Parents, mainly women and in greater number than children, state that mothers themselves, do not have any decision making role in the family.

\section{Discussions}

The National Strategy for Gender Equality, Violence to Women and Violence in the Family- NSGEVWVF, (2011-2015), has clearly defined the achievement of gender equality, that is, by eleminating gender stereotypes. Attitudes and preferences of the participants in the study showed the effects of gender stereotypes during the realization of questionnaires and interviews.

Family is the ambiance where every individual shapes the first models of behavior, including gender-based behaviors, by imitating the model role. Often in families there is no talk about gender education, only models have been offered. That is why attention must be paid when valuing all the forms of this education in this environment, mentioning here the hidden curricula`s importance (the behaviors displayed by the teachers' model role). School becomes the main and an important institution for the gender education of children, alongside the institution of the family. It can play this role by realizing specific objectives for the integration of gender education to children as suggested by the national educational policies.

Gender of the closest female/male friends is also important for both genders during the three levels of schooling but more in girls. Boys, more than girls, prefer to have girls as their friends in all the three levels of schooling whereas girls choosing to have a close male friend are rare. While they are growing, gender gaps downsize and they estimate good qualities in others. Parents share different opinions regarding the effects of gender into their children choices for female/male classmate. Mothers more than fathers think that gender does not have any effect into their children's choices of their closest male/female friends.

The effects of age and new ways of thinking regarding the possibilities for choosing professions reveal gaps 
between children and parents. Parents of both genders rank the opportunities to get employed as the main factor. Regarding students, boys share same percentages among the opportunities for employment and incomes, not only a well-paid job but even an occupation which is demanded in the market. Incomes are ranked as the main factor for schoolgirls, thinking that the economic independency will offer them more opportunities to realize themselves. The opportunity to find a job and the incomes, both factors taken together, effect into choosing professions, as stated by students of both genders. Effects of gender into choosing professions were greater in students than in parents. The percentage for both genders is equal.

Furthermore, traits classified as typical for males are often regarded more highly than those for females (such as being a doctor is better than a nurse; being physically strong is better than physically soft) (Golombok \& Fivush, 1994). There are also breaks into the gender stereotypes in the students' preferences about the profession they want to have in the future. The most favorable professions for students, for both genders, are medicine and engineering. The third place, for girls is justice, whereas boys prefer to be sportsmen. What draws attention for boys is that justice and teaching are ranked the fourth. Teaching professions and hairdressing have been considered as most preferred for girls, whereas the study reveals an increase in the percentage of boys choosing these two professions, much more than girls. The profession of the public order employees - the policemen, takes the same percentage as hairdressing. Girls draw attention by equalizing the economic branch with police studies, which has been considered as a profession for boys. The percentage of the students' perception is not the same with their parents'. This is because of the effects linked with the age gaps and the new ways of thinking regarding choices of professions.

The social-economic developments have brought new models of sharing responsibilities and performing tasks among family members. Decisions in many families are taken by both parents. There are differences of opinions among parents and students regarding the role of the father in family decision-making, which effects and is reported more by fathers and boys themselves, affecting the later as a role-model. Role of parents in decision-making is linked with their influence in the administration of the family financial incomes. A gender gap has been noticed while they argue about the father's role in administering family financial incomes. Mothers and girls ascertain that incomes are administered by both parents, whereas boys and fathers state that incomes are administered by fathers only. Administration of the family incomes are rendered more by fathers than by mothers, seizing a lower percentage than that of fathers and both parents taken together.

\section{Conclusions}

Study of new realities in the Albanian family and society highlights that:

- The existence and impact of gender stereotypes in shaping the identity of children.

- The children's development potential is ceded when gender portraying is linked with negative attitudes towards his/her.

- Society and schools are environments where gender differences appear more.

- Children create wrong concepts regarding parents responsibilities for their education, considering it as their mothers' reposnsibility, not a responsibility of both of them.

\section{Recommendations}

- Realization of the goal of education policies and strategies to eliminate gender stereotypes has not been yet achieved in a successful way. In order to actualize this goal it is necessary

- To coordinate efforts of all education actors through a concrete action plan in achieving gender parity in education and on.

- Re-dimension gender roles and models in compliance with the standards of modern society.

- Increase the awareness of the society for the state and the values of gender education for achieving gender equality.

\section{References}

Bandura, A. (1986). Social foundations of thought and action: A social cognitive theory. Englewood Cliffs NJ: Prentice-Hall. Banerjee, R. (2005). Chapter 5. Gender identity and the development of gender roles. In Ding, Sharon and Littleton, Karen (eds.) Children's Personal and Social Development. . Oxford: Blackwell Publishing Ltd. 
Berk, L. E. (2003). Child Development (Vol. 6). London: Pearson Education.

Burns, R. (1994). Introduction to Research Methods. Melburne: Pearson Education Australia.

Connell, R. (1987). Gender and Power: Society, the Person and Sexual Politics. Sydney: Cambridge: Polity Press.

David, J. C. (1984). The Social Role of School Textbooks in Canada. McGill-Queen's University Press.

Dovidio, J. F., Brigham, J. C., Johnson, B. T., \& Gaertner, S. L. (1996). Stereotyping, Prejudice, and Discrimination: Another Look. In Macrae, C. Neil, Stangor, Charles, \& Hewstone, Miles (eds.). Stereotypes and stereotyping, The Guilford Press.

Eckes, T., \& Trautner, H. M. (2000). The Developmental Social Psychology of Gender. London: Lawrence Erlbaum Associates Publishers.

Freud, S. (1925). Some psychical consequences of the anatomical distinction between the sexes. Condon: Hogarth Press.

Golombok, S., \& Fivush, R. (1994). Gender development . New York: Cambridge University Press.

Hewstone, M. (1989). Changing stereotypes with disconfirming information. In Bar-Tal, D., Graumann, C. F., Kruglanski, A. W., \& Strobe W. (eds.). Stereotypes and prejudice. Changing conceptions. New York:: Springer-Verlag.

MAS. (n.d.). Strategjia Kombëtare e Arsimit Parauniversitar 2004-2015. Retrieved 05 27, 2013, from shkollaqedua.org/wp-content/: STRATEGJIA-KOMB\%25C3\%258BTARE-E-ARSIMIT-2004-\%25E2\%2580\%2593-2015.docx

Mischel, W. (1970). Sex-typing and socialization. New York: Wiley.

Risman, B. J. (2004). Gender as a social structure: theory wrestling with activism. Gender and Society, (4 ed. vol. 18).

Stangor, C., \& Schaller, M. (1996). Stereotypes as Individual and Collective Representations. In Macrae, C. Neil, Stangor, Charles, \& Hewstone, Miles (eds.). Stereotypes and stereotyping, The Guilford Press.

Tajfel, H. (1981). Human groups and social categories. Studies in Social Psychology. Cambridge: Cambridge University Press.

UNDP. (2005). Human development report. New York: Oxford University Press.

Zemore, S. E., Fiske, S. T., \& Kim, H.-J. (2000). Gender Stereotypes and the Dynamics of Social Interaction. In Eckes, Thomas \& Trautner, Hanns M. The developmental Social Psychology of Gender, 207-242 Lawrence Erlbaum Associates Press. 
